\title{
Possibility of using RIT technology in the ground conditions of Vietnam
}

\author{
Yury Kharin ${ }^{*}$ \\ Moscow state University of civil engineering (MGCU), 129337, 26, Yaroslavskoye shosse, Moscow, \\ Russia
}

\begin{abstract}
The article compares engineering and geological conditions in the coastal areas of Vietnam and Tunisia. A sufficiently high similarity of soil structure and their physical and mechanical properties was noted. Both in Vietnam and in Tunisia, foundations for responsible buildings and structures are arranged on bored piles of the same length of 40-60 meters and a diameter of 600 to $1600 \mathrm{~mm}$. The article provides examples of using super-piles of small-size RIT using recharge impulse technology in conditions of weak water-saturated coastal soils of Tunisia. The high efficiency and cost-effectiveness of the new recharge impulse technology were noted. The article presents photographic materials of the test stand for conducting field tests of piles, presents and analyzes the results of testing piles with vertical static load. The low precipitation of the tested piles and their high load-bearing capacity prove the promise of using super-piles of RIT in the conditions of weak soils of Tunisia and, consequently, in the coastal areas of Vietnam.
\end{abstract}

\section{Engineering Geology of Vietnam and Tunisia}

Tectonically, Vietnam and Tunisia are located in the Mediterranean geo-synclinal belt, which includes sedimentary formations composed of sand and clay deposits. A characteristic feature of the engineering and geological structure of the coastal territories of Vietnam (Hanoi, Ho Chi Minh city) and Tunisia is the presence in the section of weak water-saturated soils of high power from the ground surface to a depth of $30-60 \mathrm{~m}$, having a large porosity, compressibility and low strength [1]. In both areas, the engineering and geological sections mainly represent marine (plus river in Vietnam) water-saturated clays, loams, silt deposits and Sands. The level of underground water is at a depth of $50-80 \mathrm{~cm}$ both in Vietnam and Tunisia, responsible buildings and structures are built on foundations on bored piles of the same length of 40-60 meters and a diameter of 600 to $1600 \mathrm{~mm}$. For example, one of the tallest buildings in Tunisia, the hotel "Africa", 26 stories high, was built in the $60 \mathrm{~s}$ on bored piles with a diameter of $1400-1600 \mathrm{~mm}$ and a length of $56.0 \mathrm{~m}$. The supports of the Rades-Gulet bridge were built in 2012 on bored piles with a diameter of $200 \mathrm{~cm}$ and a length of $100.0 \mathrm{~m}$. In Hanoi, until 1988, buildings with a height of 5 to 10 floors were built on bored or driven piles up to $30 \mathrm{~m}$ deep [2]. Since 1988, there has been an intensive development of the economy and construction. Most buildings between 10 and

\footnotetext{
*Corresponding author: 9651388552@mail.ru
} 
36 stories high in Hanoi and Ho Chi Minh city were built on foundations made of bored piles with a diameter of $800-1200 \mathrm{~mm}$ and a depth of up to $45 \mathrm{~m}$. It is noted that the cost of building the Foundation in such buildings is too high and reaches $30 \ldots .40 \%$ of the total cost of construction (including the cost of piles takes $22 . . .30 \%$ ) [3]. In recent years, Vietnam has built many high-rise buildings-skyscrapers. The tallest are the Landmark building, 72 stories high, built in 2011 in Hanoi, and the Bitexco Financial tower, 65 stories high, built in 2010 in Ho Chi Minh city. These tall buildings are built on massive bored piles with a diameter of 1600-2000 $\mathrm{m}$ and a depth of 45-60 m. It is clear that for such heavy high-rise buildings, it is necessary to use massive bored piles. For medium-sized buildings (8...30 floors) such piles are very expensive to use.

\subsection{Fabrication technology of RIT-piles}

In the late 90 's, geotechnics received a new type of pile with a high specific load capacity on the soil of RIT piles. Their feature is the dynamic compaction of soils in the near-mine space during their manufacture due to electrical impulses in liquid concrete. The dream of geotechnicians to compact weak soils at great depths has come true. The essence of recharge impulse technology is that a well filled with fine-grained concrete or cement mortar is treated with a series of high-voltage electrical discharges. In this case, an electrohydraulic effect occurs, which results in the formation of the body of the pile or the root of the anchor, the surrounding soil is cemented and compacted. The initial diameter of the well is $200 \ldots 350 \mathrm{~mm}$ as a result of processing a series of discharges can be increased, depending on the energy supplied to the well and the hydrogeological conditions of the site, more than 2-3 times. The surrounding soils are compacted, reducing porosity in the impact zone of the shock pulse [4].

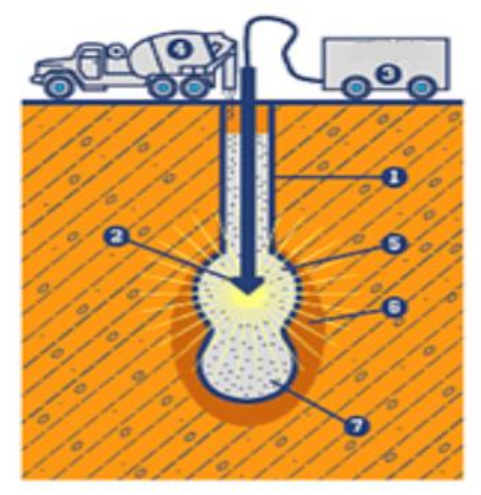

Fig. 1. Scheme of making piles-RIT.

1- W ell before processing; 2-Electrode system; 3- GIT (the generator of pulse currents); 4- Concrete pump; 5-The cementation zone of the soil; 5-Soil compaction zone; 6 - Camouflet broadening in the ground.

The impulse of a high-voltage electrical discharge affects the concrete for a fraction of a second, so the dynamic effect on nearby buildings is negligible. The process is adiabatic, so the liquid concrete is not heated at all. When the impulse is energized at $10 \mathrm{kV}$, a pressure of more than $10^{8} \mathrm{~Pa}$ occurs in the liquid concrete. Piles made using this technology have received an abbreviated name-RIT piles. In conventional units, calculated by $1 \mathrm{~m}^{3}$ in the pile body, RIT piles have a load-bearing capacity 2-3 times higher, and the cost of one ton of load-bearing capacity is 1.5-2.0 times less than that of drilling-injection and bored piles made using traditional technologies. The Russian company "MPO RITA" uses piles-RIT in 
Russia and abroad. Over the past years, the company has successfully completed pile-RIT foundations for many hundreds of buildings and structures, including pile-RIT foundations for several dozen buildings with a height of 30-45 floors in Moscow [4].

\subsection{Practical experience of RIT piles in Tunisia}

In order to expand the application of this technology, starting in 2012, pile foundations were made from piles in the weak water-saturated soils of Tunisia for ten buildings of average height from 10 to 14 floors. Only the necessary equipment for impulse processing of wells was imported to Tunisia: Impulse Current Generator (GIT), electrical cables and electrodes specially designed for this technology. Drilling of wells for piles and General construction work was carried out by a local firm «Vitello Fondation». Bored piles were made using the CFA hollow screw technology without the use of bentonite solution. A drilling machine was used for drilling «Casagrande B125».

At each construction site, the required number of hollow auger links was mounted on the drilling machine for a single pass of drilling to the required depth. In Tunisia, piles were made with a diameter of $\varnothing=320 \mathrm{~mm}$ and a depth of 12 to 22 meters, depending on the engineering and geological structure of the soil. At all construction sites where foundations were made on RIT piles in the original draft version, traditional bored piles were set with a diameter from $\varnothing=600 \mathrm{~mm}$ to $\varnothing=1200 \mathrm{~mm}$ and a depth from 35 to 56 meters. Moreover, almost always in Tunisia, piles of three or four different diameters are arranged on the same construction site, which of course extends the time for making piles. As an example, consider the production of piles for the 11-storey building "Résidence OMEGA" in the "Luc II" district of the capital of Tunisia. According to engineering and geological surveys, 7 engineering and geological elements were identified in the geological section to a depth of $40.0 \mathrm{~m}$ (the survey was performed to a depth of $60.0 \mathrm{~m}$ );

- sand of medium density, medium size, without impurities, beige color, lying from the surface of the day to a depth of $5.5 \mathrm{~m}$;

- grey silty clay with sand layers, highly compressible, in a flow-plastic state. It lies at a depth of 5.5 to $14.5 \mathrm{~m}$;

- sand of beige color, medium size, medium density. It lies at a depth of 14.5 to $17.5 \mathrm{~m}$;

- grey clay, flowable, with the inclusion of shells. It lies at a depth of 17.5 to $19.0 \mathrm{~m}$;

- the sand is silty and dusty. It lies at a depth of 19.0 to $22.5 \mathrm{~m}$;

- sand of medium density, medium size, beige color. It lies at a depth of -22.5 to $26.5 \mathrm{~m}$;

- muddy clay of gray color. It lies at a depth of 26.5 to $40.0 \mathrm{~m}$.

Initially, the Tunisian design organization developed a Foundation project of bored piles with a diameter of $\varnothing 800$ and $\varnothing 1000 \mathrm{~mm}$ and a length of $35 \mathrm{~m}$. At the suggestion of "MPO RITA", these piles were replaced with piles with a diameter of $\varnothing 320 \mathrm{~mm}$ and a length of 21 $\mathrm{m}$. The Calculation of the non-existent ability of piles for soil was performed according to Russian [5,6] and French [7] standards. According to Russian standards, the load-bearing capacity of piles on the ground was $\mathrm{Fd}=1500 \mathrm{kN}$, and the design load was $\mathrm{N}=\mathrm{Fd} / 1.4=1070$ $\mathrm{kN}$. According to French standards, the bearing capacity of piles on the ground was $\mathrm{Fd}=2151 \mathrm{kN}$, and the design load was $\mathrm{N}=\mathrm{Fdx} 0.7=1510 \mathrm{kN}$. In the final version, the Tunisian designers adopted a random load on the pile $\mathrm{N}=1000 \mathrm{kN}$.

For the preparation of fine-grained concrete, sulphate-resistant Portland cement (720 $\mathrm{kg} / \mathrm{m} 3$ ), medium-sized sand, crushed stone of $6 / 8 \mathrm{~mm}$ fraction, and superplasticizer-tor C-3 were used.

After processing the material with electrical impulses, a reinforcing frame is lowered into the mobile concrete under its own weight. 


\subsection{Field testing of vertical static load piles}

After manufacturing the entire pile field and finishing the concrete hardening, field tests of

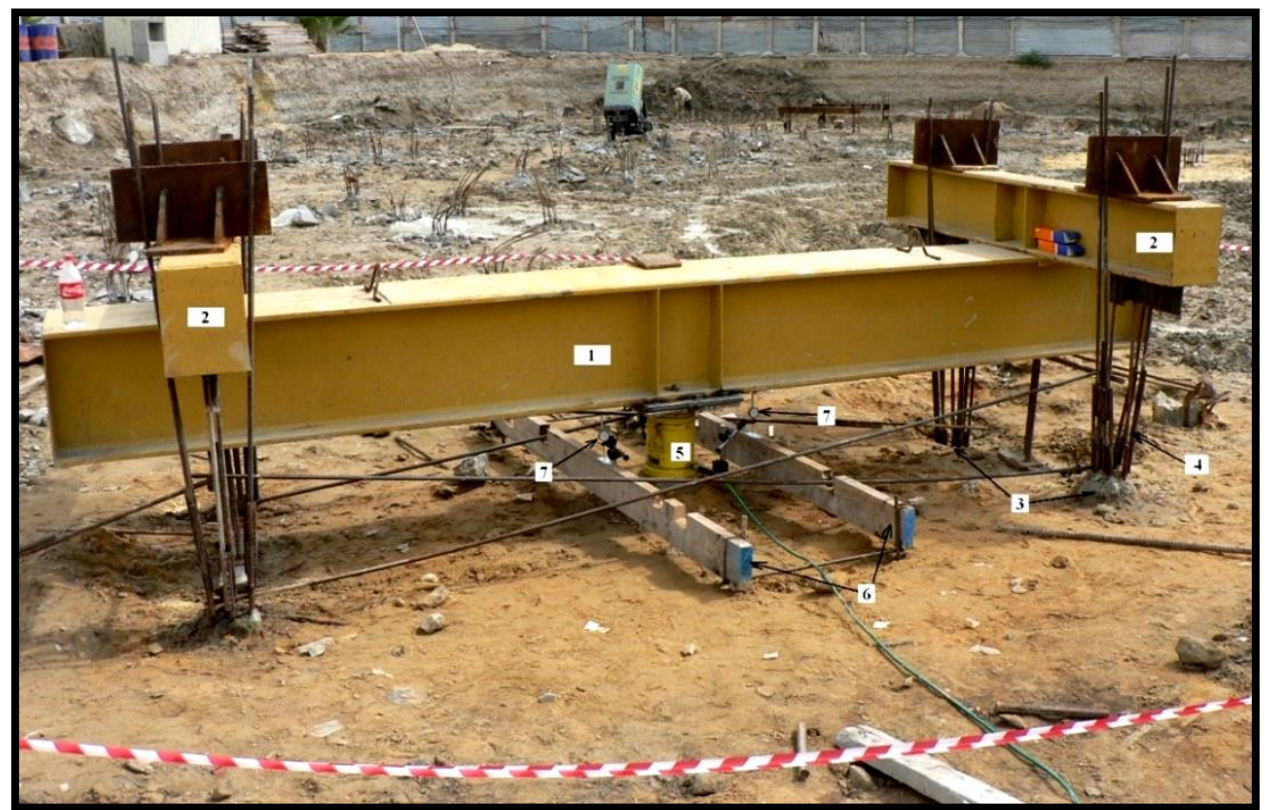

five piles were performed.

Fig. 2. General view of the test unit.

1-main beam; 2-secondary beams; 3 -anchor piles; 4-reinforcing bars that fix secondary beams; 5 hydraulic Jack; 6-reference system; 7 - indicators of movement of the clock type.

Four piles were tested with a load of $\mathrm{Q}=1550.0 \mathrm{kN}$, and one pile with a load of $\mathrm{Q}$ $=1850.0 \mathrm{kN}$. Field tests of vertical static load piles and their interpretation were carried out in accordance with the French standards NF P94-150-1 [8]. The load on the pile was applied using a hydraulic Jack with a capacity of $2000 \mathrm{kN}$ and a support structure in which four adjacent anchor piles were used to perceive the reactive forces.

Q, кн

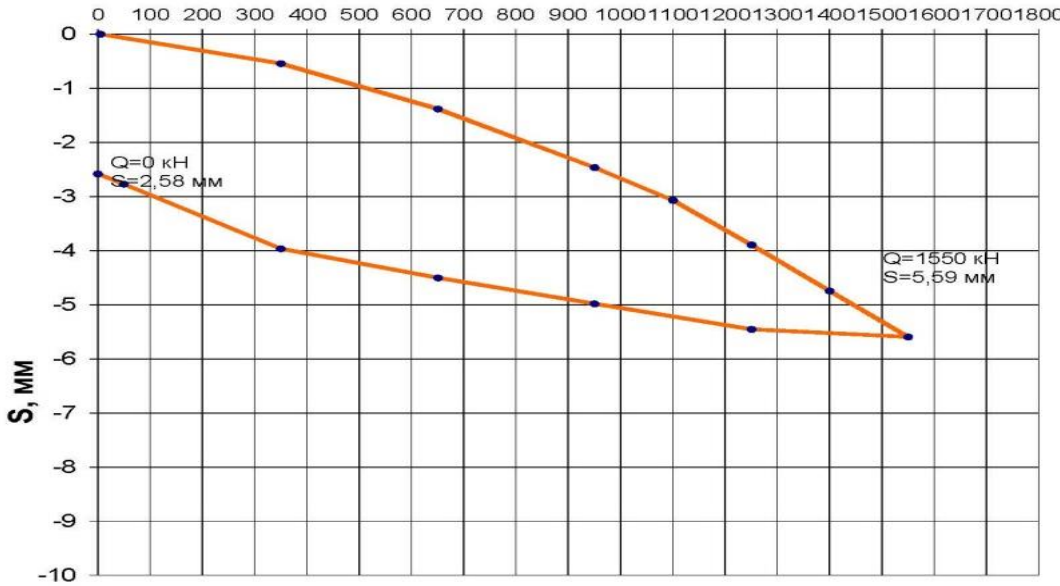


Fig. 3. Diagrams of dependence $s=f(Q)$ for the pile No. 153

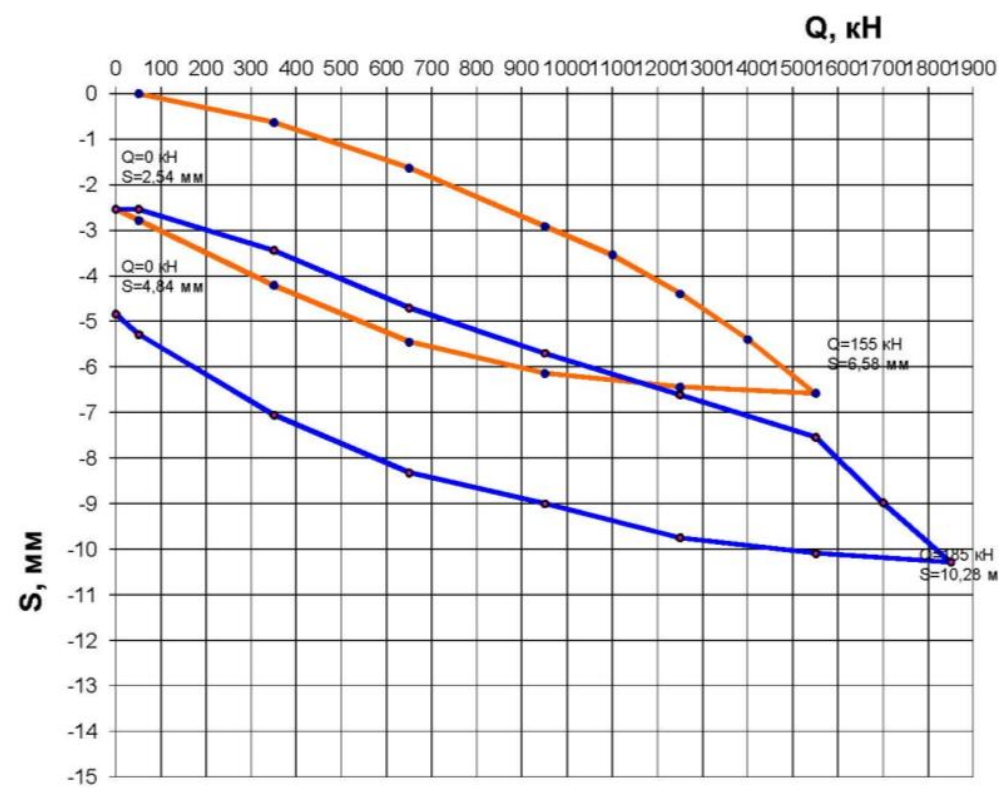

Fig. 4. Diagrams of dependence $s=f(Q)$ for the pile No. E1

The pile settling was measured using two hour-type displacement indicators with a measurement accuracy of $1 / 100 \mathrm{~mm}$ and the possibility of a $100 \mathrm{~mm}$ measuring rod running, mounted on a reference system consisting of wooden beams 3 meters long, fixed at the ends outside the zone of influence of the tested pile. The application criterion for the next load stage was the movement in $\mathrm{S}=0.1 \mathrm{~mm}$ per hour of measurement. The General view of the test unit is shown in fig. 2. Fig. 3 and Fig. 4 show the test results of one of the four piles (pile No. 153) loaded to $\mathrm{Q}=1550.0 \mathrm{kN}$ and pile $\mathrm{E} 1$ loaded to $\mathrm{Q}=1850.0 \mathrm{kN}$. The maximum settlement of pile No. 153 during loading was $5.59 \mathrm{~mm}$, and the residual settlement after unloading was $2.58 \mathrm{~mm}$. Fig. 4 shows that the load - angle graph of the stabilization curves is linear and has no fractures. Consequently, when testing the pile, loads exceeding the QC proportionality limit were not achieved [8]. The E1 pile, like the rest of the piles, was first tested to a load of $1550 \mathrm{kN}$, then, after unloading, it was reloaded to $1850 \mathrm{kN}$. During the first loading cycle, the maximum pile settlement was $6.58 \mathrm{~mm}$, the residual one was $2.54 \mathrm{~mm}$. After the second loading to $1850.0 \mathrm{kN}$, the maximum pile settlement was $10.28 \mathrm{~mm}$, and the residual one after unloading was $4.84 \mathrm{~mm}$.

\section{Conclusions}

In all cases of pile testing, the proportionality limit was not reached, and the actual bearing capacity of the piles exceeded the calculated value, both according to Russian and French standards, by 1.5-2.5 times. In addition, the precipitation of piles was significantly less than that allowed for buildings and structures. This indicates the need to further improve the methodology for calculating piles and the prospects for their use in construction on weak soils in Vietnam, Tunisia and other countries. You should pay attention to the possibility of using the French method of calculations, which are based on the results of Menard pressuremetrer tests, which allows you to get them necessary for calculating the characteristics of soils in natural occurrence. It should be noted that calculations based on 
French national standards better reflect the specifics of pile-RITS and assess their loadbearing capacity with greater reliability.

\section{References}

1. Phi Hong Thinh, L. A. Strokova, Proceedings of Tomsk Polytechnic U niversity. Georesource engineering, 328, 6-17 (2017)

2. Nguyen Quang Hing. M ethod for selecting optimal foundations for high-rise buildings in $\mathrm{Ho}$ Chi M inh city, The dissertation on competition of a scientific degree of candidate of technical Sciences, (Saint-Petersburg, 2008)

3. Dinh Hoang Nam. Interaction of long piles with soil in a pile Foundation. The dissertation on competition of a scientific degree of candidate of technical Sciences, (M oscow, 2006)

4. Stroitelstvo na fundamente znanii, B uclet, OOO «MPO RITA», 58, (M oscow, 2006)

5. SP 24.13330, Pile foundation, 85 (M oscow, 2011)

6. Technical recommendations for the design and installation of pile foundations performed using discharge-pulse technology for high-rise buildings (piles-RIT). TR 50180-06, LLC " UIC "VEK", 68, (M oscow, 2006)

7. Règles techniques de calcul et de conception des fondations des ouvrages de génie civil. Cahier des clauses techniques générales applicables aux marchés de travaux. Fascicule $\mathrm{n}^{\circ}$ 62, titre V. Ministère de l'Équipement, du Logement et des Transports. Textes Officiels, 93-3, 182 (1993)

8. NF P 94-150-1 Essai statique de pieu isolé sous un effort axial. Normes Française, AFNOR, 28 (Paris, 1999) 